\title{
Disulfide bond reconstruction: a novel approach for grafting of thiolated chitosan onto wool
}

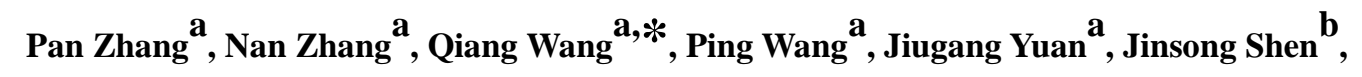

\author{
Xuerong Fan ${ }^{a}$
}

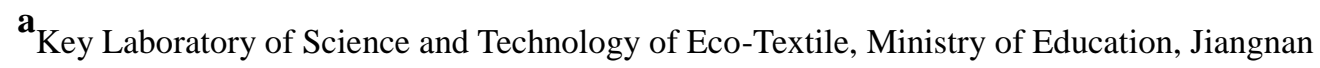

University, Wuxi, Jiangsu 214122, China

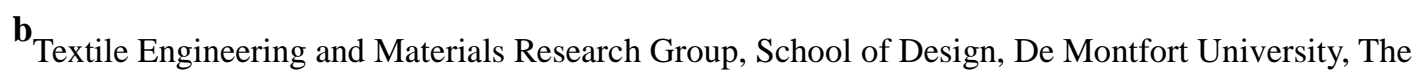
Gateway, Leicester LE1 9BH, UK

\begin{abstract}
Chitosan, a natural biopolymer, is used as a multifunctional agent for modification of wool either through chemical crosslinking or physical coating. For the first time, wool fabric has been modified with chitosan through disulfide bond breaking and reforming reactions. The chitosan was thiolated and then grafted onto the reduced wool fibers through disulfide bonds. In order to understand the mechanism of the grafting of thiolated chitosan onto wool, glutathione was used as a model compound for wool in the research. The structures of thiolated chitosan reacted with glutathione and wool fabrics grafted with thiolated chitosan were investigated by FTIR, ${ }^{13} \mathrm{CNMR}$, XPS, XRD, SEM. The dyeability, shrink-resistance and biocompatibility were also tested. The results suggested that glutathione reacted with thiolated chitosan and formed disulfide bond. The thiolated chitosan-grafted wool fabric had good shrink-resistance and dyeability. Hydrophilicity and antibacterial properties were also improved compared with untreated wool fabric. The results provide a novel approach for modification of wool through fiber-intrinsic groups like disulfide

* Corresponding author. Tel.: +86-510-85912007.

E-mail address: qiangwang@jiangnan.edu.cn.
\end{abstract}


bonds.

Keywords: Chitosan · Wool · Disulfide bond $\cdot$ Graft modification

\section{Introduction}

Chitosan, a natural polysaccharide comprising of amino-2-deoxy- $\beta$-D-glucopyranose units linked together by $\beta-(1,4)$ glycosidic bonds, has received much attention in recent years (Pradip Kumar Dutta, Dutta, \& Tripathi, 2004). The primary amino groups impart special characteristics to chitosan, such as biocompatibility, film-forming ability, and antibacterial properties that make chitosan useful in a number of industrial applications, such as pharmaceuticals (Zhou et al., 2013), paper-making (Pradip Kumar Dutta et al., 2004), food (Friedman \& Juneja, 2010), cosmetics (Harish Prashanth \& Tharanathan, 2007), textiles (Muzaffar, Bhatti, Zuber, Bhatti, \& Shahid, 2016), and other industries (Dev, Neelakandan, Sudha, Shamugasundram, \& Nadaraj, 2005). Materials of the surface modified with chitosan are widely used for corrosion resistance (Kumar et al., 2017), controlled release of drugs (Li et al., 2016), antibacterial agents (Ghimire, Luo, Tang, Sun, \& Deng, 2014; Kara, Aksoy, Yuksekdag, Hasirci, \& Aksoy, 2014), fouling resistance (Hegab, Wimalasiri, Ginic-Markovic, \& Zou, 2015), and adsorption of oil (Samadi, Yazd, Abdoli, Jafari, \& Aliabadi, 2017).

Wool is a common textile material, which can be modified by chitosan to improve its anti-felting, dyeing, anti-bacterial and other properties (Inamdar, 2014). Modification of wool with chitosan can be achieved either by coating or by using crosslinking agents (Chang \& Huang, 2012). For example, Ranjbar-Mohammadi et al. grafted chitosan onto wool fibers using anhydride cross-linking agent to impart wool with anti-bacterial property (M Ranjbar-Mohammadi, Arami, Bahrami, Mazaheri, \& Mahmoodi, 2010). Davidson et al. improved the dyeability of wool by pre-coating wool fabrics with chitosan using a pad-dry method (Davidson \& Xue, 2010). Furthermore, wool can be modified with chitosan by a combination of physical treatments using UV (Periolatto, Ferrero, Vineis, \& Rombaldoni, 2013), ultrasonic (Marziyeh Ranjbar-Mohammadi, Bahrami, \& Arami, 2013), and plasma sources (Erra et al., 1999; Shahidi, Ghoranneviss, \& Sharifi, 2014), biological treatments like enzymatic methods (Jovanĉić, Jocić, Molina, Juliá, \& Erra, 2001; Vílchez, Manich, Jovancic, \& Erra, 2008), and other treatments (Yang, Wang, Huang, \& Hon, 2010). However, these techniques usually lead to poor durability, residual toxic substances, 
damage to material matrix, deterioration of physical properties like handle and color, and also other issues (Douthwaite \& Lewis, 2010). Therefore, development of new alternative pathways for modification is necessary for functionalization of wool. Considering that wool is a keratinous material, rich in cysteine residues and contains disulfide linkages (-S-S-), the disruption and reconstruction of these inherent groups can provide a novel approach for modification and functionalization of wool textiles.

In the present work, a novel and facile approach for grafting of chitosan onto wool fabric was developed. The disulfide bonds in the cuticle scales of wool fibers were reduced to thiol groups. Then the thiol groups were reacted with thiolated functional molecules like thiolated chitosan through reconstruction of the disulfide bond (Scheme 1). Glutathione, as a model compound for wool, was used to understand the mechanism of grafting of chitosan onto wool via reconstruction of disulfide bonds. It was found that successful rearrangement of fiber-intrinsic disulfide bond for grafting thiolated chitosan on the modified wool provides a new path for wool functionalization, which is distinct from the conventional modification of keratinous or keratin-contained materials.

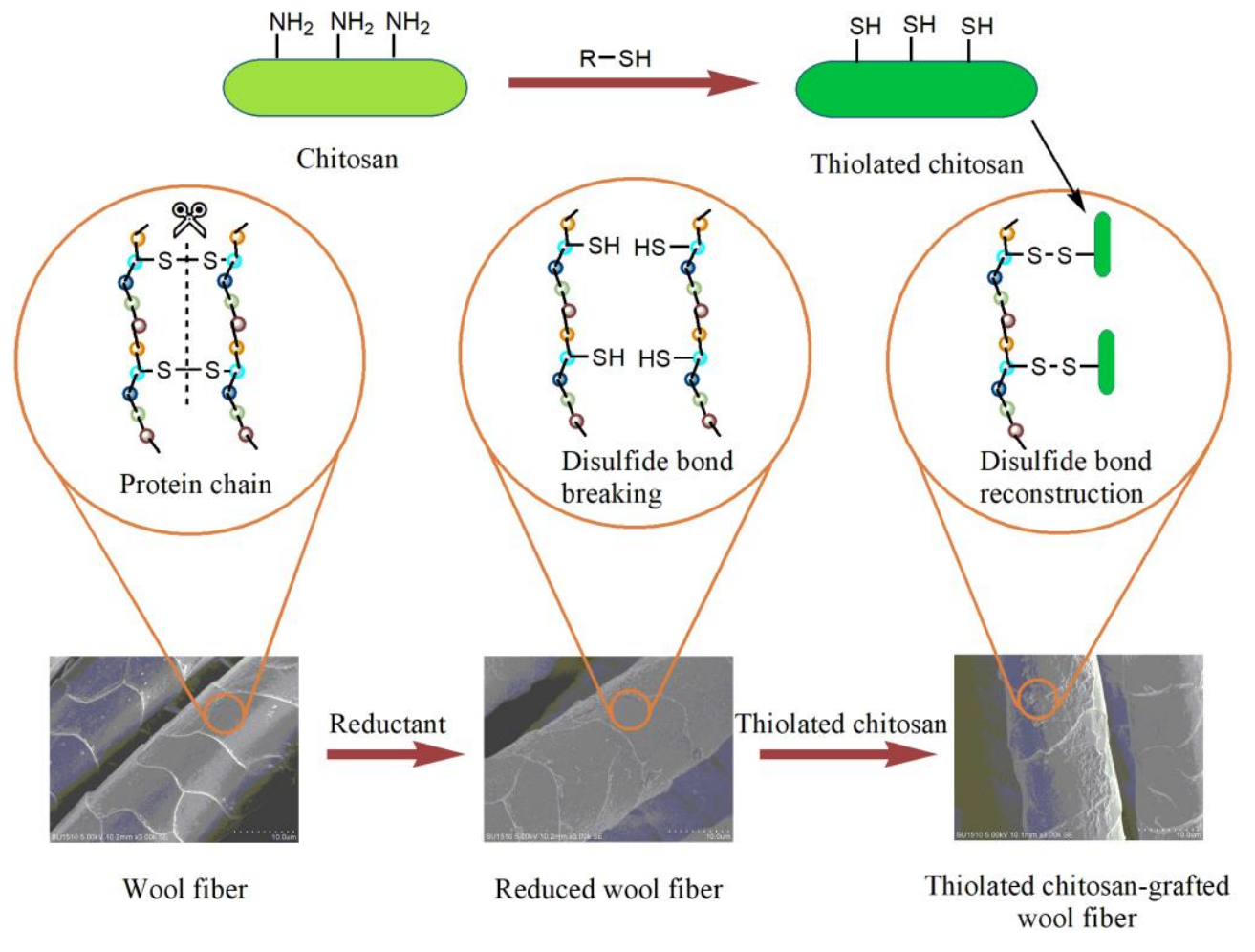

Scheme 1. Schematic illustration of the grafting reaction between chitosan and wool fiber

\section{Experimental}

\subsection{Materials}


Chitosan with 75-85\% deacetylation and molecular weight (Mw) of 50,000-190,000 Da was purchased from Sigma-Aldrich (Shanghai, China) and $\mathrm{N}$-acetyl-L-cysteine and glutathione were purchased from Aladdin (Shanghai, China). All other chemicals were of analytical grade.

\subsection{Preparation of thiolated chitosan}

Thiolated chitosan was prepared according to a previously reported procedure (Lee et al., 2007). Chitosan (0.5 g, $0.003 \mathrm{~mol})$ was dissolved in $50 \mathrm{~mL}$ deionized water containing $\mathrm{N}$-acetyl-L-cysteine (0.979 g, $0.006 \mathrm{~mol})$ and 1-(3-dimethylaminopropyl)-3-ethylcarbodiimide (EDAC) $(0.58 \mathrm{~g}, 0.003 \mathrm{~mol})$ in a shaking bath. The $\mathrm{pH}$ of reaction mixture was adjusted to 5 using $\mathrm{NaOH}$ solution $\left(5 \mathrm{~mol} \mathrm{~L}^{-1}\right)$ and the reaction took place under shaking agitation at room temperature for $3 \mathrm{~h}$ in the dark. After the reaction, the reaction mixture was precipitated in anhydrous ethanol, washed three times with ethanol, and then dried at $50{ }^{\circ} \mathrm{C}$. The product was ground into powder and preserved at $4{ }^{\circ} \mathrm{C}$. The extent of thiol modification of chitosan was determined by measuring the number of thiol groups spectrophotometrically using Ellman's reagent, at a wavelength of $412 \mathrm{~nm}$ (Wei et al., 2016).

\subsection{Grafting of glutathione onto thiolated chitosan}

Thiolated chitosan $(0.2 \mathrm{~g}, 45.07 \mu \mathrm{mol}$ thiol groups $)$ was added to the acetate solution $(0.1$ mol L $\left.{ }^{-1}, \mathrm{pH} 3.53\right)$ containing the dimethyl sulfoxide $(10 \%(\mathrm{v} / \mathrm{v}))$ and glutathione $(0.069 \mathrm{~g}, 225.36$ $\mu$ mol thiol groups) in a shaking bath at $45{ }^{\circ} \mathrm{C}$ for $18 \mathrm{~h}$. After the reaction, the product was dialyzed in deionized water for $48 \mathrm{~h}$, during which water was refreshed every $4 \mathrm{~h}$, followed by freeze drying.

\subsection{Pretreatment and reduction of wool}

Wool fabrics were extracted with acetone for $24 \mathrm{~h}$ using Soxhlet extractor prior to use. The wool fabric $(5 \mathrm{~g})$ was pre-treated for $1 \mathrm{~h}$ in $250 \mathrm{~mL}$ solution of L-cysteine $(1.5 \mathrm{~g})$ at $60{ }^{\circ} \mathrm{C}$. The sample was then washed with water and placed in anhydrous ethanol under ultrasonic oscillation for $30 \mathrm{~min}$. The degree of reduction was determined by measuring the number of thiol groups spectrophotometrically at a wavelength of $412 \mathrm{~nm}$ using Ellman's reagent (Wei et al., 2016).

\subsection{Modification of wool fabrics}

\subsubsection{Grafting of thiolated chitosan onto wool fabric}

The pre-treated wool fabrics $(5 \mathrm{~g})$ was incubated in acetate buffer $\left(0.5 \mathrm{~mol} \mathrm{~L}^{-1}, 100 \mathrm{~mL}, \mathrm{pH}\right.$ 3.53) containing thiolated chitosan and dimethyl sulfoxide (10\% (v/v)) in a shaking bath. The 
mixture was maintained at a temperature of $30{ }^{\circ} \mathrm{C}$ for the grafting reaction for $18 \mathrm{~h}$. After the reaction, the finished wool was washed with acetate solution $\left(0.5 \mathrm{~mol} \mathrm{~L}^{-1}\right)$ and deionized water.

\subsubsection{Preparation of chitosan-adsorbed wool fabric}

For comparison, the pre-treated wool fabrics $(5 \mathrm{~g})$ was incubated in acetate buffer $(0.5 \mathrm{~mol}$ $\mathrm{L}^{-1}, 100 \mathrm{~mL}, \mathrm{pH} 3.53$ ) containing chitosan only in a shaking bath. The mixture was maintained at $30{ }^{\circ} \mathrm{C}$ for $18 \mathrm{~h}$ for adsorption of chitosan on wool. The finished wool was washed with acetate solution $\left(0.5 \mathrm{~mol} \mathrm{~L}^{-1}\right)$ and deionized water.

The graft yield $(G Y)$ of chitosan on wool fibers was calculated from the changes in the concentrations of chitosan, before and after the grafting reaction. The concentrations of chitosan solutions were measured according to previous research (Wang et al., 2014; H. Xu et al., 2009). Chitosan reacts stoichiometrically with bromocresol green (BG), leading to an increase in the absorbance of BG solution at $620 \mathrm{~nm}$ due to the formation of chitosan-BG complex. A standard curve was obtained by plotting the absorbances at $620 \mathrm{~nm}$ for different concentrations of chitosan using a 2802 S Spectrophotometer (Unico Instruments, China). Linear relationship between the absorbance and chitosan concentration, ranging up to $1.0 \mathrm{mg} \mathrm{mL}^{-1}$, was obtained and is shown in Equation (1).

$$
Y=0.19009 X+0.02229
$$

Where, $X$ is the concentration of chitosan, $Y$ represents the absorbance at $620 \mathrm{~nm}$, and the correlation coefficient is 0.9965 . The residual solutions after grafting and the liquor from washing cycles (wool fabric was washed three times with deionized water) were mixed and diluted to the same volume. The different concentrations of chitosan solutions were calculated according to Equation (1). Considering that chitosan is an amino-rich polysaccharide and can adsorb onto the wool surface via Coulomb's forces under mild acidic conditions, the exact GYs of chitosan should be calculated according to Equation (2).

$$
G Y(\%)=100 \times\left(A_{2}-A_{1}\right) / A_{0}
$$

Where $A_{0}$ is the absorbance of the original chitosan solution; and $A_{1}$ and $A_{2}$ represent the absorbances of the residual solutions with and without the addition of dimethyl sulfoxide, respectively. The buffer solution as well as dimethyl sulfoxide showed no effects on the absorbance at the specified wavelength.

\subsection{Characterization of glutathione-grafted thiolated chitosan}


FTIR spectra of thiolated chitosan and chitosan grafted with glutathione using $\mathrm{KBr}$ pellet method were recorded on a Nicolet IS10 Infrared Spectrophotometer (Thermo Nicolet, USA) in the wavelength range 500-4000 $\mathrm{cm}^{-1}$ at a resolution of $4 \mathrm{~cm}^{-1}$ and 32 scans per sample. The thiolated chitosan and the final product were dissolved in a solution mixture comprising of $95 \%$ $\mathrm{D}_{2} \mathrm{O}$ and $5 \% \mathrm{DCl}$ for recording the ${ }^{13} \mathrm{C}-\mathrm{NMR}$ spectra using an AVANCE $400 \mathrm{MHz}$ spectrometer (Bruker, Germany).

\subsection{Characterization of thiolated chitosan-grafted wool}

The surface morphologies of wool samples were studied using a SU-1510 Scanning Electron Microscope (Hitachi, Japan) that operated at a typical accelerating voltage of $5 \mathrm{kV}$. Wool fabrics were sputter-coated with a thin layer of gold prior to scanning.

X-ray photoelectron spectroscopy (XPS) analysis of wool samples was carried out using a RBD upgraded PHI-5000C ESCA system (Perkin Elmer). The general spectra in the range 0 $1100 \mathrm{eV}$ and narrow spectra at high resolution for all elements were recorded.

The X-ray diffraction (XRD) patterns of wool fibers were obtained using a D2 PHASER X-ray Diffractometer (Bruker, Germany). Test parameters: copper target $\mathrm{CuK} \alpha(\lambda=0.15406)$, power $1600 \mathrm{~W}(40 \mathrm{~kW}, 40 \mathrm{~mA})$, scan range $5^{\circ}-50^{\circ}$, scan speed $4^{\circ} \mathrm{min}^{-1}$, step size $0.02^{\circ}$.

\subsection{Properties of thiolated chitosan-grafted wool fabric}

\subsubsection{Physical and mechanical properties of thiolated chitosan-grafted wool fabric}

The shrink-resistance of thiolated chitosan-grafted wool fabric was determined by measuring area shrinkage. According to the Woolmark Test Method TM31: Washing of Wool Textile Products, the samples were subjected to a 7A wash cycle for relaxation shrinkage and 5A wash cycles up to 3 times for felting shrinkage using an Electrolux Wascator FOM 71washing machine. The temperature for each of the washing cycles was $40{ }^{\circ} \mathrm{C}$. Polyester fabric make-weights were used to make up the washing load to $2 \mathrm{~kg}$ for each washing cycle. The fabric sample was conditioned for $24 \mathrm{~h}$ before measurement of the shrinkage in length in both the warp and weft directions, and finally the area shrinkage was calculated according to Equation (3).

$$
\text { Area felting shrinkage }(\%)=100 \times\left(S_{0}-S_{1}\right) / S_{0}
$$

Where $S_{0}$ is the area of fabric before washing and $S_{1}$ represents the area of fabric after washing.

The surface wettability of wool fabrics was evaluated by water contact angle measurements 
and wetting time. Before the measurements, the wool fabric samples were conditioned to moisture equilibrium in a standard atmosphere with a relative humidity of $65 \pm 5 \%$ at $21 \pm 1^{\circ} \mathrm{C}$. Then, the contact angle was measured using a JC2000D4 Contact Angle Meter (Zhongchen, China). For each sample, readings were recorded from five spots and averaged for the results. The wool fabric was fixed on the platform of the contact angle meter and a drop of water was dropped on it. The wetting time was recorded when the droplets completely infiltrated into the wool fabric. Measurements for each sample were made 5 times, and the results were averaged.

Tensile strengths of wool fabrics were determined according to ISO13934.1, using a YG(B) 026D - 250 Fabric Tensile Strength Tester (Wenzhou Darong, China). The results were expressed as breaking strength (maximum load) in the warp direction. The alkali solubility of wool fabric was evaluated using the standard method ASTM D1283-85 (Kiro 2017). Wool fabric oven-dried at $105{ }^{\circ} \mathrm{C}$ for 15 minutes was weighed as original weight and then was incubated in a beaker containing $100 \mathrm{~mL}$ of $0.1 \mathrm{~mol} / \mathrm{L}$ sodium hydroxide at $65^{\circ} \mathrm{C}$ for $1 \mathrm{~h}$. The residues were filtered and rinsed six times with distilled water and dried in an oven at $105{ }^{\circ} \mathrm{C}$ for $1 \mathrm{~h}$ and weighted. Afterwards, the alkali solubility of the samples was calculated as a percentage of the original weight. Values are the average of three replicates.

\subsubsection{Dyeability of thiolated chitosan-grafted wool}

The dyeing was performed using Acid ANOSET TB at 4\% owf at a liquor ratio of 100: 1 (pH 4.0, adjusted with $2 \mathrm{~g} \mathrm{~L}^{-1}$ acetate solution). The dyeing procedure was as follows. The initial temperature was set at $40{ }^{\circ} \mathrm{C}$ followed by a temperature rise of $3{ }^{\circ} \mathrm{C} \min ^{-1}$ up to $90{ }^{\circ} \mathrm{C}$. The dyeing process was held at $90{ }^{\circ} \mathrm{C}$ for $30 \mathrm{~min}$. At the end of dyeing process, the wool fabric was rinsed with cold water and dried at $50{ }^{\circ} \mathrm{C}$. Color Measurement Spectrophotometer (New Windsor, USA) was used for determining the color strength of dyed wool fabric, expressed as $K / S$ value (Park \& Jin, 2001).

Dye exhaustion of dyed wool fabrics was calculated from the changes in the absorbances at $420 \mathrm{~nm}$ of dyeing liquor, before and after the dyeing process, according to Equation (4).

$$
\text { Dyeing exhaustion }(\%)=100 \times\left(A_{0}-A_{1}\right) / A_{0}
$$

Where $A_{0}$ is the absorbance of original dye liquor at $420 \mathrm{~nm}$ and $A_{1}$ is the absorbance of residual dye liquor at $420 \mathrm{~nm}$.

The washing fastness of dyed wool fabrics was measured following the standard method of 
domestic and commercial laundering. The wool fabric was used as the adjacent fabric to evaluate the color staining. Rubbing fastness tests were carried out under dry and wet conditions according to the ISO 105-X12:2001 standard.

The color durability was determined by color retention rate according to Equation (5).

$$
\text { Color retention rate }(\%)=100 \times\left(K_{0}-K_{1}\right) / K_{0}
$$

Where $\mathrm{K}_{0}$ is the $\mathrm{K} / \mathrm{S}$ value before washing and $\mathrm{K}_{1}$ is the $\mathrm{K} / \mathrm{S}$ value after washing.

\subsubsection{Antibacterial properties of thiolated chitosan-grafted wool}

The antibacterial activities of thiolated chitosan-grafted wool fabric against E. coli were tested according to the standard method GB/T 20944.3-2008. Wool samples ( $0.50 \mathrm{~g})$ were cut into pieces and added into separate flasks, each containing $50 \mathrm{~mL}$ phosphate buffer solution. The concentration of the prepared inoculum was approximately $2.5 \times 10^{5} \mathrm{CFU} \mathrm{mL}^{-1}$. Five milliliters of the inoculum were added into each flask and incubated at $37{ }^{\circ} \mathrm{C}$ for $18 \mathrm{~h}$. Finally, $1 \mathrm{~mL}$ of the suspension containing bacteria was taken from each flask, and 10-fold serial dilutions were subsequently made for quantitative measurement. After incubation for $24 \mathrm{~h}$ at $37^{\circ} \mathrm{C}$, the numbers of colony forming units on the dishes of Enumeration agar were recorded. The bacterial livability for the wool fabrics were computed according to Equation (6).

$$
\text { Bacterial livability }(\%)=100 \times C / C_{0}
$$

Where $C_{0}$ is the CFUs of control group and $C$ is the CFUs of wool fabric samples. Each measurement was carried out three times.

\section{Results and Discussion}

\subsection{Characterization of thiolated chitosan and glutathione-grafted thiolated chitosan}

Considering the fact that glutathione is a low molecular weight (307 Da) water-soluble tripeptide compound with thiol groups, which is similar to wool fiber, glutathione was chosen as the model compound for wool. Glutathione was coupled with thiolated chitosan to study the mechanism of grafting of chitosan onto wool via disulfide bonds. Structural characteristics of chitosan thiolated and further grafted with glutathione were investigated by FTIR and ${ }^{13} \mathrm{C}-\mathrm{NMR}$ spectroscopy. 


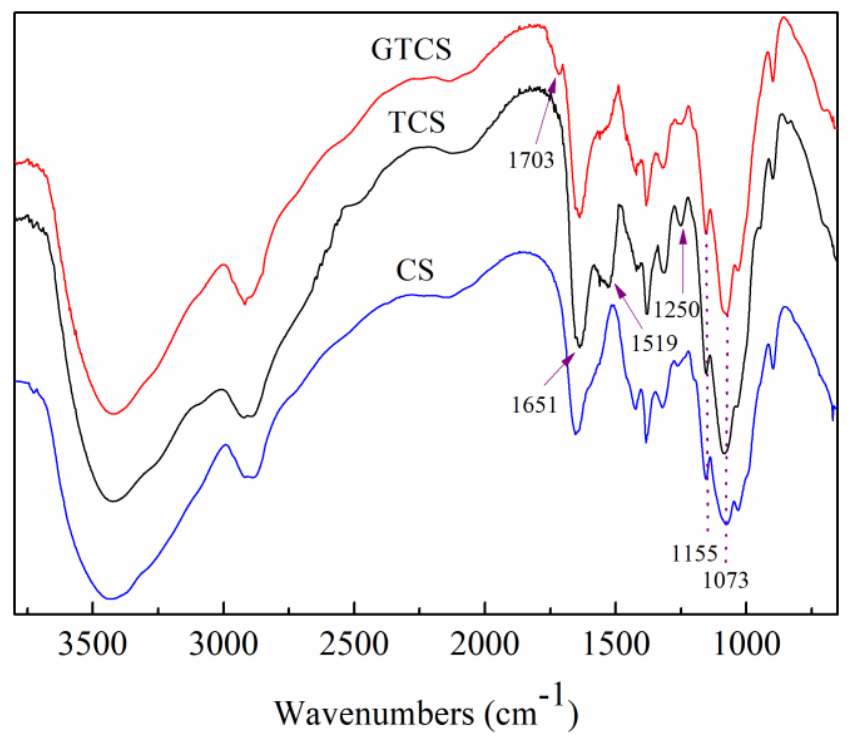

Fig. 1. FT-IR spectra of chitosan (CS), thiolated chitosan (TCS), and glutathione-grafted thiolated chitosan (GTCS).

FT-IR spectra of chitosan (CS) and thiolated chitosan (TCS) and thiolated chitosan grafted with glutathione (GTCS) are shown in Fig. 1. Peaks for C-O-C and C-O stretching are seen around $1155 \mathrm{~cm}^{-1}$ and $1073 \mathrm{~cm}^{-1}$. The characteristic peak of primary amino groups at $3440 \mathrm{~cm}^{-1}$ decrease slightly in the spectrum of TCS because the primary amino groups of chitosan "partly" reacted with the carboxyl groups of $\mathrm{N}$-acetyl-L-cysteine resulting in amide bonds, so the unreacted primary amino groups in the structure of TCS still show characteristic adsorption at $3440 \mathrm{~cm}^{-1}$ (Ren, Yan, Zhou, Tong, \& Su, 2017). Additional peaks of the newly formed amide bonds in TCS and GTCS are observed. These peaks for the amide groups appear at $1519 \mathrm{~cm}^{-1}$ (amide II band) and $1651 \mathrm{~cm}^{-1}$ (amide I band), whereas the peak at $1250 \mathrm{~cm}^{-1}$ corresponds to thiol groups (Anitha et al., 2011). Moreover, compared with chitosan (CS) and thiolated chitosan (TCS), in the spectrum of chitosan grafted with glutathione (GTSC), the invisible peak of - $\mathrm{COOH}$ which only present in the structure of glutathione at $1703 \mathrm{~cm}^{-1}$ confirms there are covalent crosslink between glutathione and thiolated chitosan.

The ${ }^{13} \mathrm{C}-\mathrm{NMR}$ spectra of chitosan and thiolated chitosan grafted with glutathione were analyzed to confirm the findings of FTIR spectroscopy. It is evident from Fig. 2 that chitosan has 6 different carbon atoms: $\delta=97.28 \mathrm{ppm}, \delta=55.76 \mathrm{ppm}, \delta=69.82 \mathrm{ppm}, \delta=76.43 \mathrm{ppm}, \delta=74.73$ ppm, and $\delta=60.18 \mathrm{ppm}$ are the shifts for $\mathrm{C} 1, \mathrm{C} 2, \mathrm{C} 3, \mathrm{C} 4, \mathrm{C} 5$, and C6, respectively (Abdelmalek, Sila, Haddar, Bougatef, \& Ayadi, 2017). Comparing with chitosan, the peaks between 50 ppm $100 \mathrm{ppm}$ do not change in the spectrum of thiolated chitosan grafted with glutathione. Peaks at 
170-175 ppm correspond to the -CONH- and -OCO- groups in $\mathrm{N}$-acetyl-L-cysteine and glutathione structures. New peaks at $35 \mathrm{ppm}-53 \mathrm{ppm}$ correspond to $-\mathrm{CH}_{2}$ and $-\mathrm{CH}-$ of $N$-acetyl-L-cysteine and glutathione. In addition, the peaks $25.29 \mathrm{ppm}$ and $30.96 \mathrm{ppm}$ are attributed to $-\mathrm{CH}_{2}-\mathrm{S}$ - and -CH-S- functional groups of $\mathrm{N}$-acetyl-L-cysteine and glutathione, indicating that glutathione successfully reacted and connected with thiolated chitosan through disulfide bonds. The results are consistent with FTIR analysis, which indirectly provides evidence for similar grafting reaction between wool and chitosan.

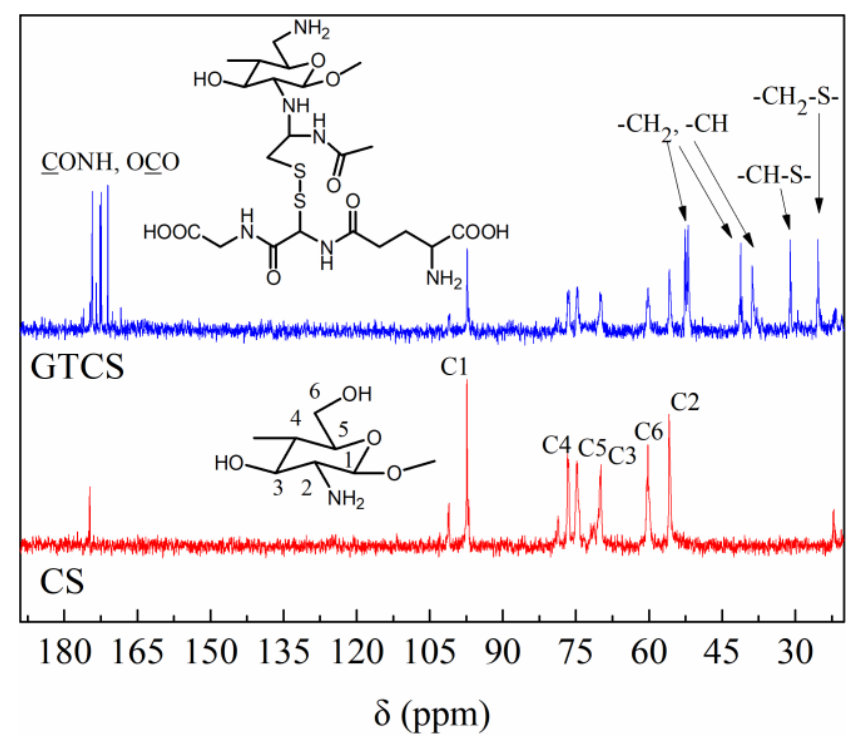

Fig.2. ${ }^{13} \mathrm{C}-\mathrm{NMR}$ spectra of chitosan (CS) and glutathione-grafted thiolated chitosan (GTCS).

\subsection{Characterization of thiolated chitosan-grafted wool fibers}

The number of thiols in thiolated chitosan reached to $225.35 \mu \mathrm{mol} / \mathrm{g}$ after thiol modification of chitosan. The pretreated wool fabric contained $18.25 \mu \mathrm{mol} / \mathrm{g}$ thiol groups after wool fabric was reduced to break its disulphide bonds by optimum reacting conditions. non-toxic and amino acid L-cysteine in the pretreatment process. Therefore, the thiolated chitosan can be grafted on the reduced wool fabric via reforming disulfide bonds between thiol groups of wool and chitosan.

Graft yields of chitosan onto wool fabrics were determined by measuring the changes in concentrations of chitosan after treatments. The change in concentration of chitosan for the reaction of wool with chitosan in the absence of dimethyl sulfoxide reached $3.78 \%$, which occurred mainly due to the adsorption of chitosan onto wool fabrics via hydrogen bonds and van der Waals forces. he graft yield for the wool grafted with thiolated chitosan in the presence of dimethyl sulfoxide went up to $7.43 \%$, suggesting that higher amount of chitosan was covalently 
bonded to the wool surface via disulfide bond between wool and thiolated chitosan.
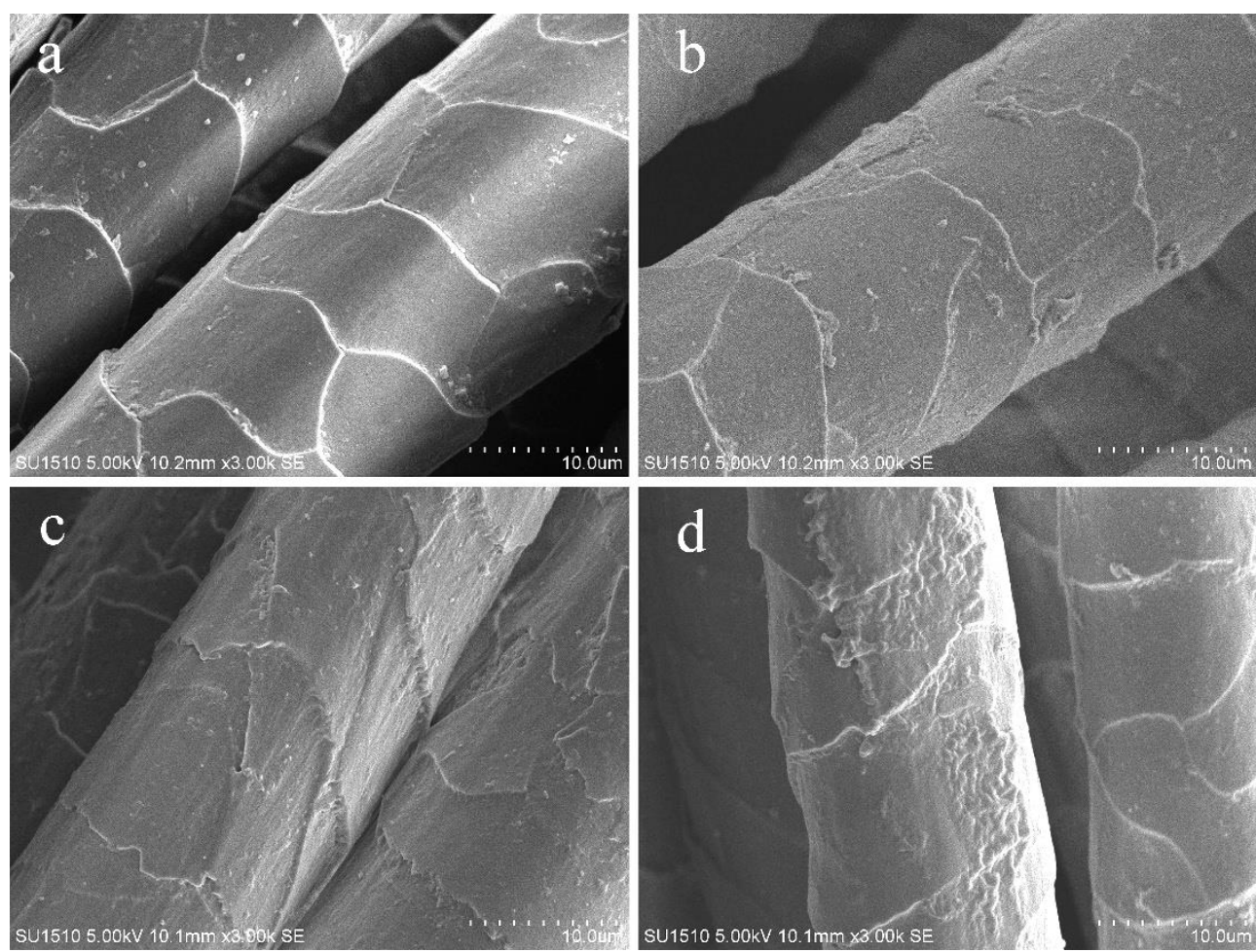

Fig.3. Surface morphologies of untreated wool (a), L-cysteine-pretreated wool (b), chitosan-adsorbed wool (c), and thiolated chitosan-grafted wool (d).

Fig. 3 shows characteristic SEM images of untreated wool fiber (a), L-cysteine-pretreated wool fiber (b), chitosan-adsorbed wool fiber (c), and thiolated chitosan-grafted wool fiber (d). The surface layer scales of untreated wool fiber (Fig. 3a) appeared very clear and intact. On the other hand, the surface of the pre-treated wool sample (Fig. 3b) showed some damage with appearance of fragments of scales. The partial breaking of the disulfide bonds in the keratin during reduction pre-treatment of wool fiber could cause slight damage, resulting in formation of the cracked cuticle particles on the surface of the wool fibers. From the images of chitosan-adsorbed sample (Fig. 3c) and thiolated chitosan-grafted sample (Fig. 3d), a thin coating can be seen on the scaly surface of the fibers. And the thiolated chitosan-grafted sample had coating thicker than chitosan-adsorbed wool sample. These results demonstrate not only the adsorption of chitosan onto wool fibers but also covalent bonding of chitosan on the surface of wool fiber because of the disulfide bond between thiolated chitosan and the reduced wool fiber.

Surface elemental compositions (C, O, N, and S) of wool fabrics were determined by XPS analysis. The XPS analysis depth on the fibre surface is about $0.5-5.0 \mathrm{~nm}$, so it can reflect the change in the surface structure of wool fibers from different treatments (Lucovsky, Yang, Chao, 
Tyler, \& Czubatyj, 1983; Richardson \& Johnston, 2007; Ward et al., 1993). The results are shown in Fig. S1 and Table S1. According to the XPS spectra of wool fabrics (Fig.S1), four characteristic peaks can be observed in the range of $0-600 \mathrm{e} V$ of wool XPS energy spectrum for $\mathrm{C} 1 \mathrm{~s}$ peak (285e V), N 1s peak (400e V), O 1s (532e V) and S (164e V) (Ke, Yu, Xu, Cui, \& Shen, 2008; Tang et al., 2011). There was no difference between the $\mathrm{C} / \mathrm{N}$ ratio of untreated wool and that of chitosan-adsorbed sample, but the $\mathrm{C} / \mathrm{N}$ ratio of thiolated chitosan-grafted sample increased. This might be because that the thiolated chitosan can form covalent bonding with the pretreated wool fiber, increasing the content of C element (Bensalem et al., 2017; Yu, Pang, Zhang, Zhou, \& Wei, 2018). In pretreatment process, the scales of the wool were partially removed, resulting in a decrease of sulfur element, so that the C/S ratio of modified wool samples increased when compared with untreated wool. In addition, the content of thiol group in thiolated chitosan was $225.35 \mu \mathrm{mol} / \mathrm{g}$. The $\mathrm{C} / \mathrm{S}$ ratio of thiolated chitosan was much higher than that of wool fiber. Therefore, when the thiolated chitosan was grafted on to wool fiber, the increase of C element was more than that of $\mathrm{S}$ element, resulting in the $\mathrm{C} / \mathrm{S}$ ratio of thiolated chitosan-grafted sample increased when compared with chitosan-adsorbed sample.

The XPS spectra of the samples were also exploited to investigate the chemical bonds on the wool sample surface. The relative contents of carbon bonds such as $\mathrm{C}-\mathrm{C}, \mathrm{C}-\mathrm{H}$ and $\mathrm{C}-\mathrm{O}$ were investigated to know how the carbon bonds on the surface of wool fibers were changed. XPS spectrum of C 1s (Fig.4a, b, c) fits three peaks, which are 284.5 e V ( C-C and C-H, mainly derived from fiber surface fatty acid and peptide chain molecules), 286.2e V(C-O and C-N), $288 \mathrm{e}$ V(O-C-O and -C=O) (Molina, Espinós, Yubero, Erra, \& González-Elipe, 2005). Compared with XPS spectrum of C1s from the untreated wool (Fig. 4A), the content of C-C and C-H in modified wool (Fig. 4B, C) increased. Besides, the content of C-N and C-O in modified wool increased with $6 \%$ compared to that of the untreated wool. This increase might be due to the additional chitosan, more $\mathrm{C}$ element appeared in the surface of wool fiber. The area of C-C, C-H of thiolated chitosan-grafted wool sample was more than chitosan-adsorbed sample, indicating that thiolated chitosan formed disulfide bond with the pretreated wool fiber resulting in more thiolated chitosan on wool fiber. The decreases of area of C-O, C-N in thiolated chitosan-grafted sample also could demonstrate the result that more chitosan was grafted onto wool fiber in thiolated chitosan-grafted sample. 

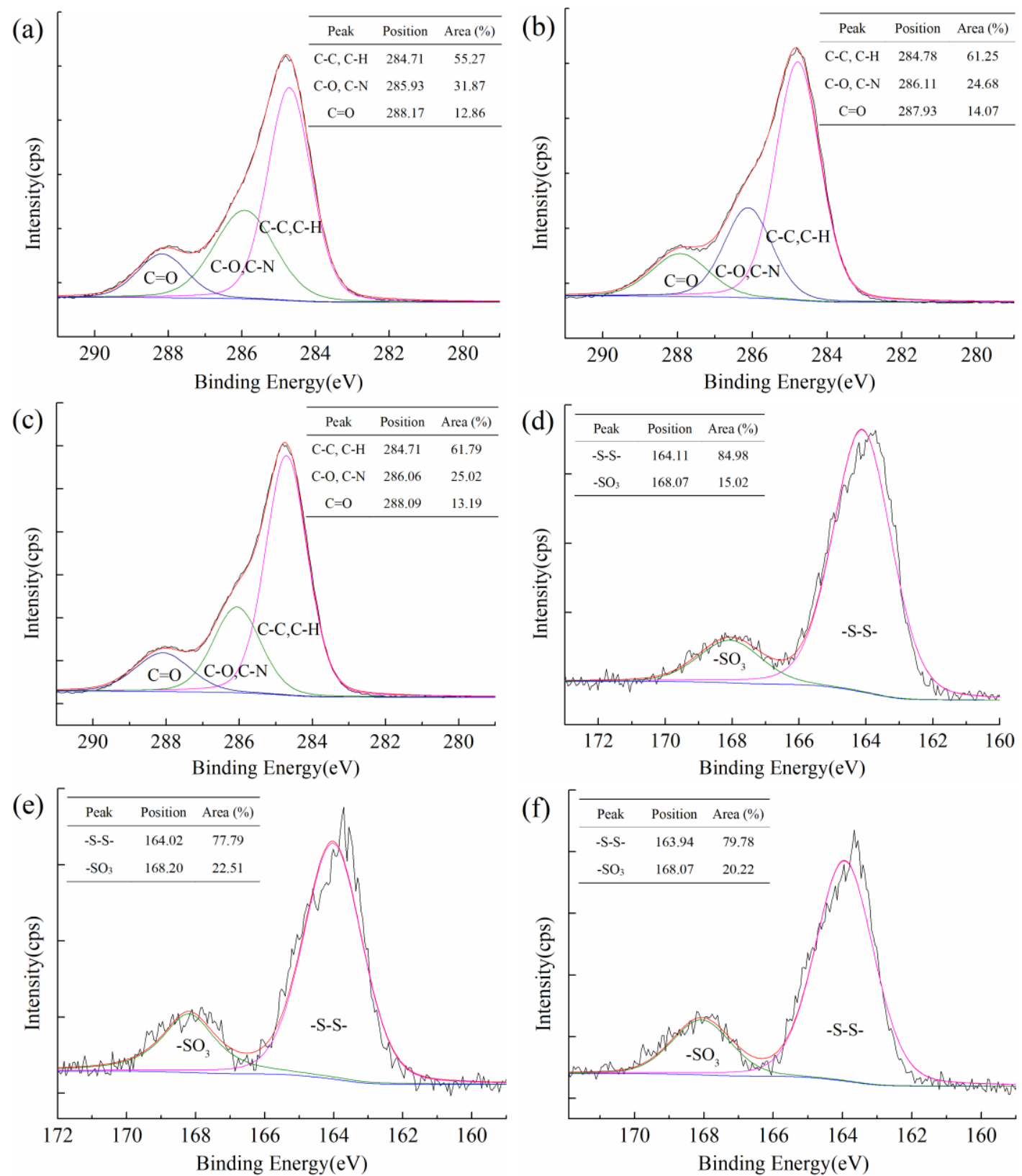

Fig.4. XPS spectra of C1s from (a) the untreated wool, (b) chitosan-adsorbed sample, (b) thiolated chitosan-grafted sample and S 2p from (d) the untreated wool, (e) chitosan-adsorbed sample, (f) thiolated chitosan-grafted sample.

The XPS spectra of S 2p for wool fabrics are displayed in Fig. 4, and there were two peaks of S(II) (-S-S-) and S(IV) (-SO $\left.\mathrm{S}_{3} \mathrm{H}\right)$ (Kan \& Yuen, 2006). The content of -S-S- in untreated wool (Fig. 4d) is more than the two modified wool sample. That was because the -S-S- bond in the wool fiber was reduced into - $\mathrm{SH}$ after pretreatment and then reformed back to either $-\mathrm{S}-\mathrm{S}$ - or $-\mathrm{SO}_{3} \mathrm{H}$ in the reaction with thiolated chitosan or chitosan. The content of -S-S- in thiolated chitosan-grafted sample (Fig.4C) increased compared to that of chitosan-adsorbed sample testifying that thiolated 
chitosan has reformed disulfide bond with pretreated wool fiber which consistent with the result as above-mentioned C 1s. The results indicated that thiolated chitosan was grafted onto wool fiber via disulfide bonds.

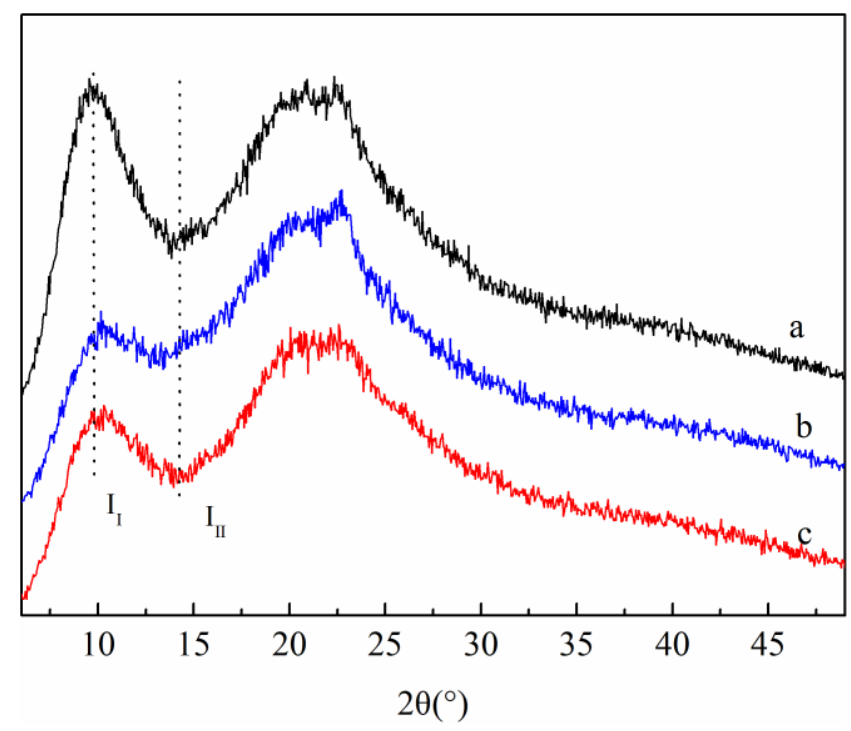

Fig.5. XRD spectra of untreated wool fiber (a), chitosan-adsorbed sample (b), and thiolated chitosan-grafted sample (c).

Effects of inter- and intra-molecular interactions on the crystalline structure of modified fiber were studied by X-Ray Diffractometry (XRD). Fig. 4 illustrates the typical diffraction patterns of wool fiber with $2 \theta=9-10^{\circ}$ and $15-31^{\circ}$, corresponding to the $\alpha$-helical and $\beta$-sheet-like structures of wool fibers, respectively, and $2 \theta=14^{\circ}$ due to its amorphous nature (Cao, 2000; Nishikawa, Tanizawa, Tanaka, Horiguchi, \& Asakura, 1998; W. Xu, Ke, Wu, \& Wang, 2006). As can be seen from Fig. 4 , the $\alpha$-folded crystallinity of wool fiber decreases and the diffraction peak at $9.6^{\circ}$ of the untreated fiber shifts to $10.4^{\circ}$ after treatment. The crystallization index $(C I)$ of wool fiber was calculated using Equation (5) (Segal, Creely, Martin, \& Conrad, 1959) and the results are presented in Table 1.

$$
C I(\%)=100 \times\left(I_{I}-I_{I I}\right) / I_{I}
$$

Where $I_{\mathrm{I}}$ is the maximum intensity at around $2 \theta=9^{\circ}$ and $I_{\mathrm{II}}$ is the minimum intensity near $2 \theta$ $=14^{\circ}$.

Table 1 The crystallization indexes of wool fiber.

\begin{tabular}{lcccc}
\hline Wool Sample & $I_{\mathrm{I}}$ & $I_{\mathrm{II}}$ & $C I(\%)$ & Relative $C I(\%)$ \\
\hline Untreated wool fiber & 1602 & 823 & 48.63 & 100 \\
Chitosan-adsorbed wool fiber & 759 & 555 & 26.88 & 55.27 \\
Thiolated chitosan-grafted wool fiber & 926 & 607 & 34.45 & 70.84 \\
\hline
\end{tabular}

According to the crystallization indexes of wool fibers shown in Table 1, the crystallization index of chitosan-adsorbed wool fiber decreased significantly when compared to the untreated 
wool fiber. This might be due to the partial breaking of the disulfide bonds in the wool fiber during the reduction pretreatment with L-cysteine, resulting in the degradation of the wool fiber. However, the crystallization index of the chitosan-grafted sample was higher than that of the chitosan-adsorbed wool sample. Chitosan can not only absorb on the surface of wool fiber but also enter into the porous space of the fiber via Van der Waals forces and hydrogen bonds. The thiol groups in thiolated chitosan and reduced wool fiber can reform disulfide bond within the fiber. Chitosan-grafted wool also have higher amount of chitosan coated on the fiber. These could make the chitosan-grafted wool sample recovered in the crystallinity. These could make the chitosan-grafted wool sample recovered in the crystallinity and the internal part of wool fibers was not damaged.

\subsection{Physical and mechanical properties of chitosan-grafted wool fabric}

Table 2 Tensile strength, shrink-resistance and wetting property of the modified wool fabrics

\begin{tabular}{lccccc}
\hline Fabric Sample & $\begin{array}{c}\text { Tensile } \\
\text { strength } \\
(\mathrm{N})\end{array}$ & $\begin{array}{c}\text { Alkali } \\
\text { solubility } \\
(\%)\end{array}$ & $\begin{array}{c}\text { Area } \\
\text { shrinkage } \\
(\%)\end{array}$ & $\begin{array}{c}\text { Water } \\
\text { contact } \\
\text { angle }\left(^{\circ}\right)\end{array}$ & $\begin{array}{c}\text { Wetting time } \\
(\mathrm{min})\end{array}$ \\
\hline Untreated wool & 559.3 & 4.23 & 9.76 & 126.87 & 19.47 \\
& $( \pm 1.21)$ & $( \pm 0.22)$ & $( \pm 0.31)$ & $( \pm 0.55)$ & $( \pm 0.33)$ \\
Water-treated wool & 551.4 & 4.11 & 5.92 & 125.32 & 19.21 \\
& $( \pm 1.37)$ & $( \pm 0.25)$ & $( \pm 0.28)$ & $( \pm 0.60)$ & $( \pm 0.45)$ \\
Chitosan-adsorbed wool & 473.8 & 6.93 & 3.05 & 121.67 & 11.27 \\
& $( \pm 1.77)$ & $( \pm 0.33)$ & $( \pm 0.53)$ & $( \pm 0.43)$ & $( \pm 0.41)$ \\
Thiolated chitosan-grafted & 490.8 & 6.42 & 2.06 & 115.44 & 9.58 \\
wool & $( \pm 1.98)$ & $( \pm 0.37)$ & $( \pm 0.66)$ & $( \pm 0.57)$ & $( \pm 0.57)$ \\
\hline
\end{tabular}

The physical and mechanical properties of treated wool fabrics were assessed and the results are presented in Table 2. The tensile strength of treated wool fabrics showed a general decline compared with untreated fabric. This was because wool fabric had been slightly damaged especially in the cuticle surface of the fiber during reduction pretreatment. However, the tensile strength of thiolated chitosan-grafted fabric remained higher than that of the chitosan-adsorbed wool fabric. That is due to the fact that chitosan could form a layer of coating on the surface of wool fiber. Thiolated chitosan was also grafted onto the wool fabric through the cross-linking of protein molecules, resulting in the increase in the strength of wool fabric. Thus, the polymerization of chitosan on wool fiber surface could strengthen the wool fabric. The alkali solubility of wool fabrics undergoing different treatments (see Table 2) draws the same conclusion as above-mentioned the tensile strength. It further confirmed that the method of disulfide bond reformation caused less damage to thiolated chitosan-grafted wool fabric than chitosan-adsorbed 
wool fabric.

The wool fabric was treated with deionized water under the same conditions of temperature, agitation and time as those of other samples in order to know the relaxation shrinkage of the wool fabrics for comparison. Area shrinkage of untreated wool fabric (Table 2) reached 9.76\%, while that of the water-treated sample was 5.92\%. The area shrinkage of thiolated chitosan-grafted wool fabric was further reduced to $2.16 \%$. It was also found that the hydrophilicity of treated fabrics was also significantly improved. The water contact angle and wetting time decreased compared with untreated fabric, due to a large number of hydrophilic hydroxyl and amino groups from chitosan. In general, wool fabrics modified with thiolated chitosan showed significant improvements in anti-felting and wetting properties.

3.4 Dyeing properties of thiolated chitosan-grafted wool fabric

Table 3 Dyeing properties of the modified wool fabrics

\begin{tabular}{|c|c|c|c|c|c|c|}
\hline \multirow[t]{2}{*}{ Fabric sample } & \multirow[t]{2}{*}{$\begin{array}{l}\text { Dye } \\
\text { exhaustion } \\
(\%)\end{array}$} & \multirow[t]{2}{*}{$K / S$ values } & \multirow{2}{*}{$\begin{array}{l}\text { Color } \\
\text { retention rate } \\
(\%)\end{array}$} & \multicolumn{2}{|c|}{$\begin{array}{l}\text { Rubbing } \\
\text { fastness }\end{array}$} & \multirow[t]{2}{*}{$\begin{array}{l}\text { Wash } \\
\text { fastness }\end{array}$} \\
\hline & & & & Dry & Wet & \\
\hline Untreate & $59.21( \pm 1.02)$ & $26.62( \pm 0.87)$ & $94.73( \pm 0.74)$ & 4 & 3 & $4-5$ \\
\hline $\begin{array}{l}\text { Chitosan-adsorbed } \\
\text { wool }\end{array}$ & $87.63( \pm 0.75)$ & $28.40( \pm 0.96)$ & $95.53( \pm 0.65)$ & 4 & 3 & $4-5$ \\
\hline $\begin{array}{l}\text { Chitosan-grafted } \\
\text { wool }\end{array}$ & $91.68( \pm 1.53)$ & $31.98( \pm 1.28)$ & $98.72( \pm 1.38)$ & 4 & $3-4$ & 5 \\
\hline
\end{tabular}

The performances of the wool fabric modified with chitosan and untreated fabric were studied by dyeing with an acid dye. Table 3 shows that the incorporation of chitosan can remarkably increase the dye exhaustion and $K / S$ values of the wool fabric. This is due to the protonated amino groups in chitosan, which increase the electrostatic attractions between the wool fibers and the anions of the acid dye, under acidic conditions. Scales are obstacles in wool dyeing, and hence generally high temperature dyeing accelerates the diffusion of dye into interior of fibers. Chitosan tends to deposit between the scales and adsorb more negatively charged dyestuffs. Therefore, the dye exhaustion of modified fabrics was found to be significantly higher compared to untreated one under the same dyeing conditions. However, no significant increase in dye exhaustion and $K / S$ values was observed between wool modified by chemical grafting and by physical adsorption. Table 3 also shows the effect of grafting thiolated chitosan on the color 
fastness of wool fibers. There was almost no difference in dry rubbing fastness between modified fabrics and untreated fabric. However, wet rubbing fastness of modified fabric grafted with thiolated chitosan was better than that of the untreated fabric. This indicated that the covalent bonding between thiolated chitosan and the wool fabrics made higher color fastness than the adsorption between chitosan and wool fabrics. In addition, the washing fastness also supports these findings. The wash fastness of thiolated chitosan-grafted fabric was better than that of chitosan-adsorbed fabric. The color retention rate of the chitosan-grafted sample was higher than that of chitosan-adsorbed sample, which also reveals that the covalent linkage between chitosan and wool fiber adsorbs more chitosan and subsequently dyestuffs on the wool fiber. The thiolated chitosan-grafted wool fabric shows a good color durability.

\subsection{Antibacterial properties of thiolated chitosan-grafted wool fabric}

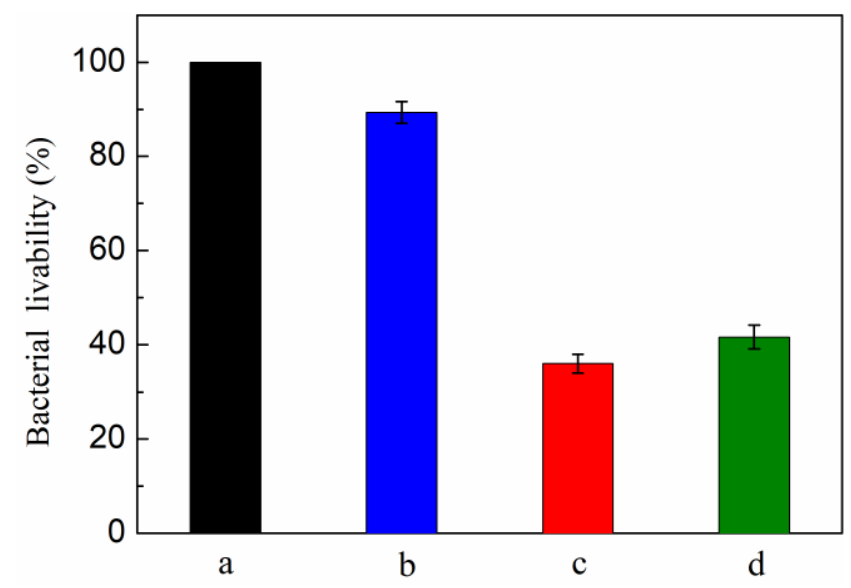

Fig.6. Bacterial livabilities of blank (a), untreated wool (b), chitosan-adsorbed wool (c), and thiolated chitosan-grafted wool (d).

Antibacterial activities of modified wool fabrics were determined by the shake flask testing method. The results are shown in Fig. 5. Untreated wool was ineffective against E. coli, whereas modified wool fabric showed a bacteriostatic rate up to $58.32 \%$, which indicated a certain antibacterial effect of chitosan. However, the bacteriostatic rate of chitosan-adsorbed wool fabric was $63.96 \%$, slightly less than that of wool grafted with chitosan. The generally accepted explanation for the antibacterial properties of chitosan is that the reactive amino groups can interact with negatively charged cell membranes of bacteria (P. K. Dutta, Shipra, Mehrotra, \& Joydeep, 2009). Thiolation of chitosan decreases the number of free amino groups on wool, causing a slight weakening of the antibacterial property of chitosan-grafted sample. Nevertheless, 
the antibacterial activities of chitosan-adsorbed wool fabric were better than the untreated one.

\section{Conclusions}

Thiolated chitosan-grafted wool fabric was obtained through disulfide bond reconstruction of wool fabrics with thiolated chitosan. Glutathione, as the model compound of wool, was reacted with thiolated chitosan to study the mechanism of grafting of thiolated chitosan onto wool fiber. FT-IR and ${ }^{13} \mathrm{C}-\mathrm{NMR}$ analyses provided theoretical evidences for the grafting of thiolated chitosan onto wool via disulfide bond reconstruction. Characterization of thiolated chitosan-grafted wool fibers showed that the graft yield of thiolated chitosan on wool fiber was up to $7.43 \%$, with a slight decrease in crystallinity. The thiolated chitosan-grafted wool fabric showed significant improvements in shrink-resistance compared to untreated wool fabric. The area shrinkage of thiolated chitosan-grafted wool fabric was reduced to $2.06 \%$ after $7 \mathrm{~A}$ and 3 times $5 \mathrm{~A}$ washing cycles. Performance of thiolated chitosan-grafted wool fabric on antibacterial properties, dyeing ability, and other properties was improved. Accordingly, the approach used herein can be extended to other keratinous or keratin-containing materials, thereby expanding the scope of application of these materials.

\section{Acknowledgements}

This work was financially supported by the National Key R\&D Program of China (2017YFB0309200); the National Natural Science Foundation of China (51673087, 31771039); the Program for Changjiang Scholars and Innovative Research Teams in Universities (IRT_15R26); Fundamental Research Funds for the Central Universities (JUSRP51717A); National first-class discipline program of Light Industry Technology and Engineering (LITE2018-21).

\section{References}

Abdelmalek, B. E., Sila, A., Haddar, A., Bougatef, A., \& Ayadi, M. A. (2017). $\beta$-chitin and chitosan from squid gladius: Biological activities of chitosan and its application as clarifying agent for apple juice. International Journal of Biological Macromolecules, 104.

Anitha, A., Deepa, N., Chennazhi, K. P., Nair, S. V., Tamura, H., \& Jayakumar, R. (2011). Development of mucoadhesive thiolated chitosan nanoparticles for biomedical applications. Carbohydrate Polymers, 83(1), 66-73.

Bensalem, S., Hamdi, B., Confetto, S. D., Iguer-Ouada, M., Chamayou, A., Balard, H., \& Calvet, R. (2017). Characterization of chitosan/montmorillonite bionanocomposites by inverse gas chromatography. Colloids \& Surfaces A Physicochemical \& Engineering Aspects, 516, 336-344. 
Cao, J. (2000). Is the $\alpha-\beta$ transition of keratin a transition of $\alpha$-helices to $\beta$-pleated sheets? Part I. In situ XRD studies. Journal of Molecular Structure, 553, 101-107.

Chang, S. H., \& Huang, J. J. (2012). Biodegradability and anticoagulant properties of chitosan and sulfonated chitosan films coated on TiNi alloys. Surface \& Coatings Technology, 206(23), 4959-4963.

Davidson, R. S., \& Xue, Y. (2010). Improving the dyeability of wool by treatment with chitosan. Coloration Technology, 110(1), 24-29.

Dev, V. R. G., Neelakandan, R., Sudha, S., Shamugasundram, O. L., \& Nadaraj, R. N. (2005). Chitosan - A polymer with wider applications. Textile Magazine, 46, 83-86.

Douthwaite, F. J., \& Lewis, D. M. (2010). The formation of cysteine-S-sulphonate groups in wool and the effect on shrink-resistance. Coloration Technology, 110(9), 304-307.

Dutta, P. K., Dutta, J., \& Tripathi, V. S. (2004). Chitin and chitosan: Chemistry, properties and applications. Journal of Scientific \& Industrial Research, 63(1), 20-31.

Dutta, P. K., Shipra, T., Mehrotra, G. K., \& Joydeep, D. (2009). Perspectives for chitosan based antimicrobial films in food applications. Food Chemistry, 114(4), 1173-1182.

Erra, P., Molina, R., Jocic, D., Julia, M. R., Cuesta, A., \& Jmd, T. (1999). Shrinkage properties of wool treated with low temperature plasma and chitosan biopolymer. Textile Research Journal Publication of Textile Research Institute Inc \& the Textile Foundation, 69(11), 811-815.

Friedman, M., \& Juneja, V. K. (2010). Review of antimicrobial and antioxidative activities of chitosans in food. Journal of Food Protection, 73(9), 1737.

Ghimire, N., Luo, J., Tang, R., Sun, Y., \& Deng, Y. (2014). Novel anti-infective activities of chitosan immobilized titanium surface with enhanced osteogenic properties. Colloids \& Surfaces $B$ Biointerfaces, 122(122C), 126-133.

Harish Prashanth, K. V., \& Tharanathan, R. N. (2007). Chitin/chitosan: modifications and their unlimited application potential-an overview. Trends in Food Science \& Technology, 18(3), 117-131.

Hegab, H. M., Wimalasiri, Y., Ginic-Markovic, M., \& Zou, L. (2015). Improving the fouling resistance of brackish water membranes via surface modification with graphene oxide functionalized chitosan. Desalination, 365, 99-107.

Inamdar, M. S. (2014). Studies on applications of chitosan and synthesized chitosan derivatives in textile processing. Gujarat.

Jovanĉić, P., Jocić, D., Molina, R., Juliá, M. R., \& Erra, P. (2001). Shrinkage Properties of Peroxide-Enzyme-Biopolymer Treated Wool. Textile Research Journal, 71(11), 948-953.

Kan, C. W., \& Yuen, C. W. M. (2006). Surface characterisation of low temperature plasma-treated wool fibre. Journal of Materials Processing Technology, 178(1), 52-60.

Kara, F., Aksoy, E. A., Yuksekdag, Z., Hasirci, N., \& Aksoy, S. (2014). Synthesis and surface modification of polyurethanes with chitosan for antibacterial properties. Carbohydr Polym, 112(112), 39-47.

Ke, G., Yu, W., Xu, W., Cui, W., \& Shen, X. (2008). Effects of corona discharge treatment on the surface properties of wool fabrics. Journal of Materials Processing Tech, 207(1), 125-129.

Kumar, A. M., Suresh, B., Das, S., Obot, I. B., Adesina, A. Y., \& Ramakrishna, S. (2017). Promising bio-composites of polypyrrole and chitosan: Surface protective and in vitro biocompatibility performance on 316L SS implants. Carbohydrate Polymers, 173, 121-130.

Lee, D., Zhang, W., Shirley, S. A., Kong, X., Hellermann, G. R., Lockey, R. F., \& Mohapatra, S. S. (2007). 
Thiolated Chitosan/DNA Nanocomplexes Exhibit Enhanced and Sustained Gene Delivery. Pharmaceutical Research, 24(1), 157.

Li, J., Liu, D., Tan, G., Zhao, Z., Yang, X., \& Pan, W. (2016). A comparative study on the efficiency of chitosan-N-acetylcysteine, chitosan oligosaccharides or carboxymethyl chitosan surface modified nanostructured lipid carrier for ophthalmic delivery of curcumin. Carbohydr Polym, 146, 435-444.

Lucovsky, G., Yang, J., Chao, S. S., Tyler, J. E., \& Czubatyj, W. (1983). Nitrogen-bonding environments in glow-discharge-deposited films. Physical Review B, 28(6), 3234-3240.

Molina, R., Espinós, J. P., Yubero, F., Erra, P., \& González-Elipe, A. R. (2005). XPS analysis of down stream plasma treated wool: Influence of the nature of the gas on the surface modification of wool. Applied Surface Science, 252(5), 1417-1429.

Muzaffar, S., Bhatti, I. A., Zuber, M., Bhatti, H. N., \& Shahid, M. (2016). Synthesis, characterization and efficiency evaluation of chitosan-polyurethane based textile finishes. International Journal of Biological Macromolecules, 93(Pt A), 145-155.

Nishikawa, N., Tanizawa, Y., Tanaka, S., Horiguchi, Y., \& Asakura, T. (1998). Structural change of keratin protein in human hair by permanent waving treatment 1. Polymer, 39(16), 3835-3840.

Park, S. J., \& Jin, J. S. (2001). Effect of Corona Discharge Treatment on the Dyeability of Low-Density Polyethylene Film. J Colloid Interface Sci, 236(1), 155-160.

Periolatto, M., Ferrero, F., Vineis, C., \& Rombaldoni, F. (2013). Multifunctional finishing of wool fabrics by chitosan UV-grafting: an approach. Carbohydrate Polymers, 98(1), 624-629.

Ranjbar-Mohammadi, M., Arami, M., Bahrami, H., Mazaheri, F., \& Mahmoodi, N. M. (2010). Grafting of chitosan as a biopolymer onto wool fabric using anhydride bridge and its antibacterial property. Colloids \& Surfaces B Biointerfaces, 76(2), 397.

Ranjbar-Mohammadi, M., Bahrami, S. H., \& Arami, M. (2013). Eco-friendly grafting of natural biopolymer chitosan onto acylated wool fabrics using ultrasonic and study its properties. Journal of Applied Polymer Science, 129(2), 707-713.

Ren, L., Yan, X., Zhou, J., Tong, J., \& Su, X. (2017). Influence of chitosan concentration on mechanical and barrier properties of corn starch/chitosan films. International Journal of Biological Macromolecules, 105(Pt 3), 1636.

Richardson, M. J., \& Johnston, J. H. (2007). Sorption and binding of nanocrystalline gold by Merino wool fibres--an XPS study. J Colloid Interface Sci, 310(2), 425-430.

Samadi, S., Yazd, S. S., Abdoli, H., Jafari, P., \& Aliabadi, M. (2017). Fabrication of novel chitosan/PAN/magnetic ZSM-5 zeolite coated sponges for absorption of oil from water surfaces. International Journal of Biological Macromolecules, 105(Pt 1), 370.

Segal, L., Creely, J. J., Martin, A. E., \& Conrad, C. M. (1959). An Empirical Method for Estimating the Degree of Crystallinity of Native Cellulose Using the X-Ray Diffractometer. Textile Research Journal, 29(10), 786-794.

Shahidi, S., Ghoranneviss, M., \& Sharifi, S. D. (2014). Effect of Atmospheric Pressure Plasma Treatment/Followed by Chitosan Grafting on Antifelting and Dyeability of Wool Fabric. Journal of Fusion Energy, 33(2), 177-183.

Tang, B., Wang, J., Xu, S., Afrin, T., Xu, W., Lu, S., \& Wang, X. (2011). Application of anisotropic silver nanoparticles: Multifunctionalization of wool fabric. J Colloid Interface Sci, 356(2), 513-518.

Vílchez, S., Manich, A. M., Jovancic, P., \& Erra, P. (2008). Chitosan contribution on wool treatments with enzyme. Carbohydrate Polymers, 71(4), 515-523. 
Wang, P., Yu, M., Cui, L., Yuan, J., Wang, Q., \& Fan, X. (2014). Modification of Bombyx mori silk fabrics by tyrosinase - catalyzed grafting of chitosan. Engineering in Life Sciences, 14(2), 211-217.

Ward, R. J., Willis, H. A., George, G. A., Guise, G. B., Denning, R. J., Evans, D. J., \& Short, R. D. (1993). Surface analysis of wool by X-ray photoelectron spectroscopy and static secondary ion mass spectrometry. Textile Research Journal, 63(6), 362-368.

Wei, Z., Ming, K., Chao, F., Cheng, X., Liu, Y., \& Chen, X. (2016). Investigation of gelling behavior of thiolated chitosan in alkaline condition and its application in stent coating. Carbohydrate Polymers, 136, 307-315.

Xu, H., Peng, S., Wang, C., Yao, L., Sun, J., Ji, F., \& Qiu, Y. (2009). Influence of absorbed moisture on antifelting property of wool treated with atmospheric pressure plasma. Journal of Applied Polymer Science, 113(6), 3687-3692.

Xu, W., Ke, G., Wu, J., \& Wang, X. (2006). Modification of wool fiber using steam explosion. European Polymer Journal, 42(9), 2168-2173.

Yang, H. C., Wang, W. H., Huang, K. S., \& Hon, M. H. (2010). Preparation and application of nanochitosan to finishing treatment with anti-microbial and anti-shrinking properties. Carbohydrate Polymers, 79(1), 176-179.

Yu, J., Pang, Z., Zhang, J., Zhou, H., \& Wei, Q. (2018). Conductivity and Antibacterial Properties of Wool Fabrics Finished by Polyaniline/Chitosan. Colloids \& Surfaces A Physicochemical \& Engineering Aspects.

Zhou, Y., Yang, H., Liu, X., Mao, J., Gu, S., \& Xu, W. (2013). Electrospinning of carboxyethyl chitosan/poly(vinyl alcohol)/silk fibroin nanoparticles for wound dressings. International Journal of Biological Macromolecules, 53(2), 88-92. 